\title{
Study on Anti-Hygrothermal Aging Properties of TPS Hot-melt Adhesive
}

\author{
Huo Ning-bo ${ }^{1, a^{*}}$, Zhao Chun-hai ${ }^{2, b}$ \\ ${ }^{1}$ Dept.of txtile and chemical engineering , Binzhou Polytechnic College, Binzhou 256603,China \\ 2Dept.of bioengineering , Binzhou Polytechnic College, Binzhou 256603,China

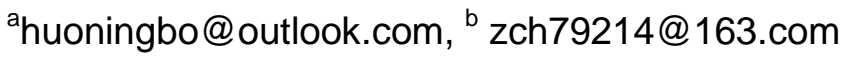

Keywords: Hygrothermal Aging, Hot-melt Adhesive, TPS

\begin{abstract}
TPS type hot-melt adhesive damp heat aging phenomenon along with the seasonal variation is analyzed. Effect of kinds and content of tackifying resin, elastomer and TPU on the properties of hot-melt adhesive bonding is studied, and with the method of orthogonal design the optimized hot-melt adhesive formula and anti-aging properties are analyzed.
\end{abstract}

\section{Introduction}

At present, in terms of the common TPS (thermoplastic styrene), the softening point of styrene is between $90-110^{\circ} \mathrm{C}$. After dilution of thickening agent and softening oil, pressure sensitive hot-melt adhesive is almost impossible to get over $100^{\circ} \mathrm{C}$ shear adhesion fail temperature. That is unable to survive in the high temperature environment for a long time[1].How to apply elastomer and tackifying resin to enhance the hot-melt pressure-sensitive adhesive performance of high temperature resistance is an important content of hot-melt adhesive research[2,3].

\section{Test Section}

Test Materials. Naphthenic oil (4010), industrial grade, Shanghai Siwo Chemical Co., Ltd.. SEBS Elastomer(Kraton G1650, Kraton G1651), industrial grade, Kraton Performance Polymers. Thermoplastic Polyurethane (Desmopan WDP85786A, Desmopan DP3685AU),industrial grade, Bayer (China) Co., Ltd.. C5 Hydrogenation Petroleum Resin (C-100R), industrial grade, Nanjing Eastman Company. Antioxygen (1010), industrial grade, Yangzi Petrochemical Co., Ltd.

Testing Instruments. Electric mixer, DJ1C-100, Xinpei Equipment (Shanghai) Co., Ltd.. Intelligent Electronic Stripping Tester, XLW-100N, Jinan Languang Mechanical and Electrical Technology Co., Ltd.. Constant Temperature and Humidity Box, HS/YH-150, Chongqing Yongsheng Experiment Instrument Factory. Softening point tester, SYD-2806,Shanghai Changji Geological Instrument Co., Ltd.. Melt viscosity tester, SNB-AI, Shanghai Nirun Intelligent Technology Co., Ltd.

Preparation of Adhesive. Select a certain amount of naphthenic oil, heated to a certain temperature, stirring gradually in the process of adding elastomer, maintain a certain temperature until the elastic body material completely molten and naphthenic oil, adding adhesive resin, heating and stirring to uniform and transparent viscous liquid, thermostatic degassing after cooling made of solid block.

Melt Viscosity Determination $\left(\mathbf{1 8 0}^{\circ} \mathrm{C}\right)$ [4]. Determination was performed according to HG/T 3660- 1999 standard. 
$\mathbf{1 8 0}^{\circ}$ Peel Strength Test. The patch will be prepared with hot-melt adhesive coating device applied to a thickness of $50 \mu \mathrm{m}$ PET single transparent silicon thin film. Determination was performed according to GB/T2792- 1998 standard.

Softening point test(R\&B). According to GB/T 15332-1994 standard.

\section{Results and Discussion}

The Bonding Performance of Hot-melt Adhesive Products. Three different batches of before optimization products were taken and stored for 8 months in an open environment conditions, hot-melt adhesive strength and melt viscosity of which were measured from July to next March.

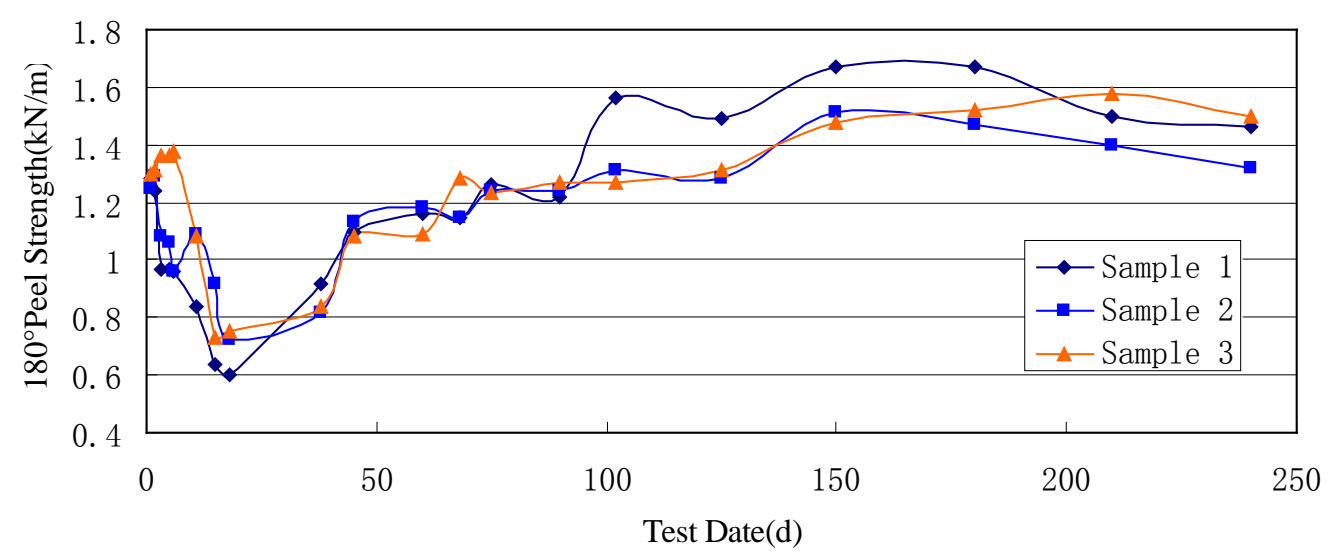

Fig. 1 The change tendency of the peel strength of the products at different time points

Adhesion properties of test samples which were stored within 60 days in July and August were greatly decreased. This is due to the production of products affected by the temperature and humidity affect the smaller on the beginning, adhesion is not affected.With the extension of storage time, higher temperature and humidity impact on the hot-melt adhesive surface or application surface, make the colloidal cohesion decrease significantly. $180^{\circ}$ peel strength decreased by 45.3\%.With the drop in temperature and humidity lower in September and October of 60 day test period, the adhesion properties of hot-melt adhesive generally enhanced. Peel strength increased by $10 \%-15 \%$ in September and about $10 \%$ in October. We can see that the possibility of hot-melt adhesive cohesion decrease under the environment of fall is low. In the period from November to March next year, with the temperature decrease, hot-melt adhesive peel strength were increased significantly.

Therefore, to ensure the hot-melt adhesive products in the storage period always to maintain good adhesion performance, the key is to solve the problem of cohesion decrease under the conditions of high temperature and high humidity.

Effect of Tackifying Resin Content on the Adhesion Properties of Hot-melt Adhesive.The C5 C-100R hydrogenation petroleum resin has better oxidation resistance than the rosin resin. Maintain the other components unchanged, increase the amount of the increase of the viscosity of the resin, test products of the peel strength and melt viscosity. 


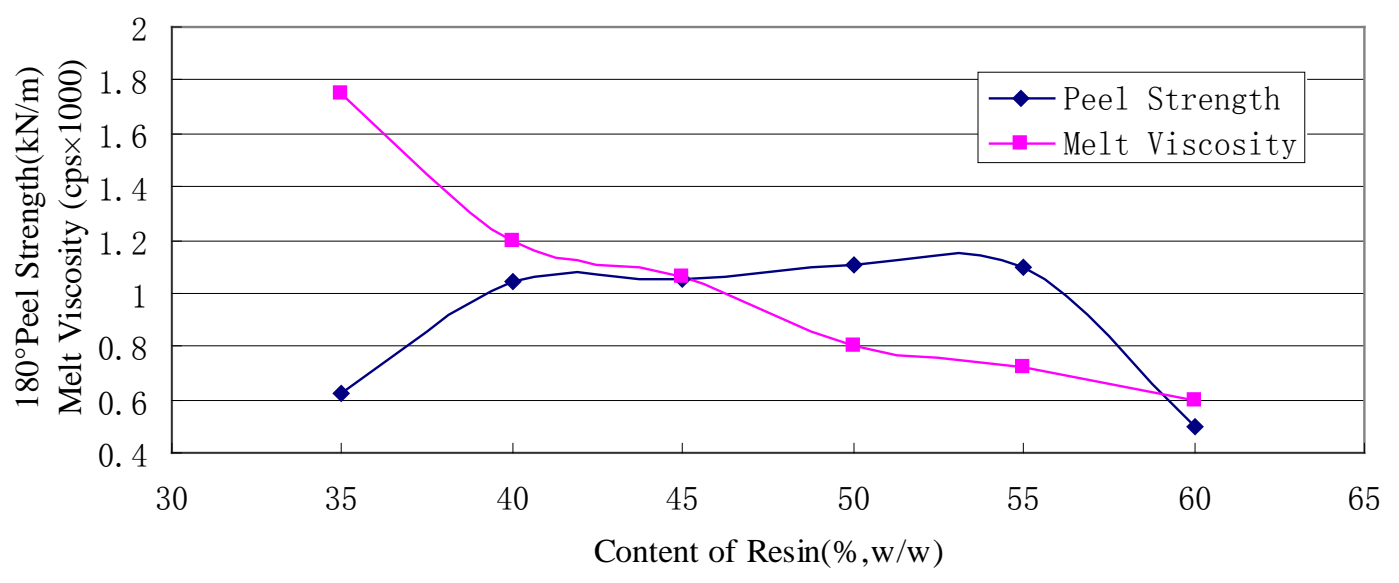

Fig. 2 Hot-melt adhesive bonding properties of different tackifying resin content

Increasing adhesive dosage will increase the melt wettability, enhance the adhesion effect. Tackifying resin softening point is low, generally in the $60-100^{\circ} \mathrm{C}$. So with the tackifying resin dosage increased, melt viscosity decreased gradually. When the amount of the resin was $60 \%$, the ratio of the elastomer decreased, the cohesive strength decreased, the characteristics of strong wettability and weak interfacial force were shown. The content of resin is better than $40 \%$. With the content of resin increases, the hardness increases. The product will melt quickly after it reaches a certain temperature. The experimental data show that the proportion of low softening point resin increases by $20 \%$ and the melt viscosity decreases by $200 \mathrm{mPa} \cdot \mathrm{s}$.

Effect of Elastomer Content on the Properties of Hot-melt Pressure Sensitive Adhesive. Compared with YH-792, YH-791, YH-796 SBS elastomer, SEBS elastomer has better oxidation resistance.Taking Kraton G1650 SEBS for example, maintaining the other points (naphthenic oil: tackifying resin =3:5) unchanged, increasing the amount of the elastomer, peeling strength, melt viscosity, initial adhesion force and shear force were tested.

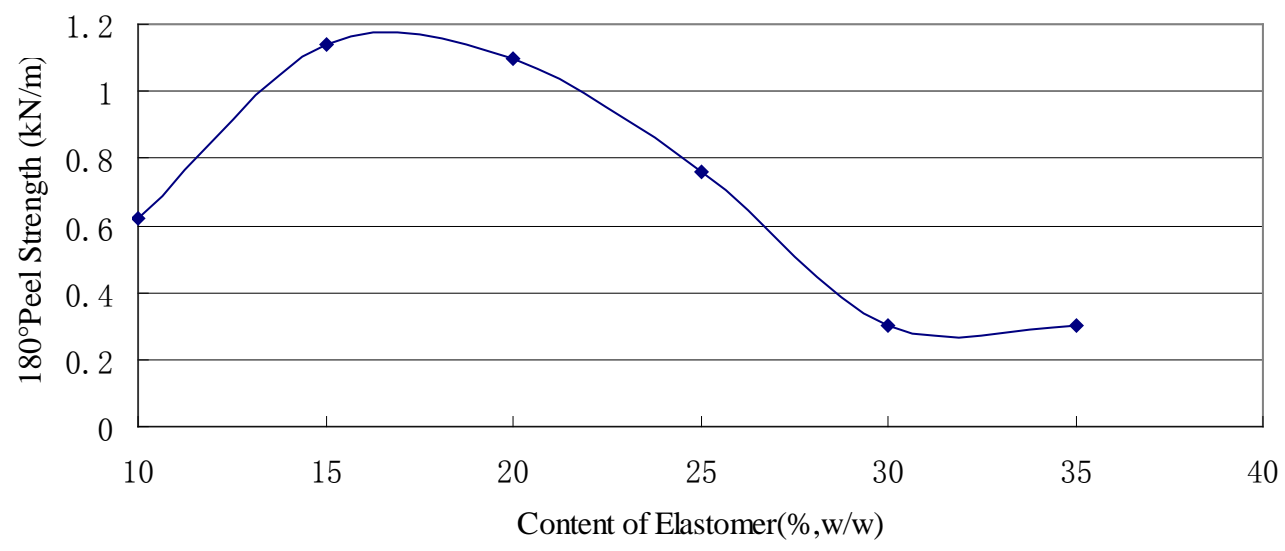

Fig. 3 Effect of elastomer content on bond properties

With the increase of elastomer content, the melt viscosity increased gradually, the surface of hot-melt adhesive cohesion increases, peel strength increases first and then decreases. This shows that with tackifying resin content was reduced, colloid and adhesion between the weak bonding materials. The trend of the change of the stick force can also reflect this point. Therefore, when the cohesion and cohesion are maintained, the bond effect is the best. The amount of elastomer should be better in $15 \%-20 \%$ range. 
Effect of TPU Content on the Properties of Hot-melt Pressure Sensitive Adhesive. Excellent ageing resistance of thermoplastic polyurethane as blending component was selected to blend with SEBS. Thermoplastic polyurethane anti-ultraviolet radiation performance of Desmopan WDP85786A is prominent, and also has a particularly high flexibility and low temperature flexibility. Maintain the other components unchanged, with TPU instead of part of SEBS or SBS, the preparation of a new type of hot-melt adhesive products, and the results were tested.

Table 1 Hot-melt adhesive parameters of different SEBS-TPU ratio

\begin{tabular}{|c|c|c|c|c|c|c|c|c|}
\hline SEBS-TPU Ratio & $95: 5$ & $90: 10$ & $85: 15$ & $80: 20$ & $75: 25$ & $70: 30$ & $65: 35$ & $60: 40$ \\
\hline $24 \mathrm{~h} 180^{\circ}$ Peel Strength $(\mathrm{kN} / \mathrm{m})$ & 1.19 & 1.21 & 1.21 & 1.23 & 1.24 & 1.25 & 1.27 & 1.32 \\
\hline 6 month $180^{\circ}$ Peel Strength $(\mathrm{kN} / \mathrm{m})$ & 0.69 & 0.73 & 0.85 & 1.05 & 1.11 & 1.15 & 1.23 & 1.28 \\
\hline Softening Point $\left({ }^{\circ} \mathrm{C}\right)$ & 69 & 70 & 71 & 73 & 76 & 77 & 82 & 88 \\
\hline $180^{\circ} \mathrm{C}$ Melt Viscosity (cps) & 670 & 810 & 950 & 1070 & 1300 & 1460 & 1800 & 2430 \\
\hline
\end{tabular}

The addition of TPU significantly improved the bond strength of the hot-melt adhesive and long-term anti-aging performance. This trend is more pronounced as the TPU ratio increases. Because TPU material of high hardness and strength is greater, with the increase of the content, especially more than a ratio of 75:25, and hot-melt adhesive products of softening point and $180{ }^{\circ} \mathrm{C}$ melting viscosity increased rapidly. This is a disadvantage for the properties of hot-melt adhesives.

Hot-melt Adhesive Prescription Optimization Experiment. According to the above the results of single factor experiments, content of Elastomer (A), TPU (B), Resin (C) and 1010 antioxidant(D) as the four factors, 3 levels with each factor, four factors three levels orthogonal experiment table was designed, as shown in Table 2.

Table 2 Orthogonal design of composition optimization

\begin{tabular}{|l|l|l|l|l|}
\hline No. & $\mathrm{A}(\%)$ & $\mathrm{B}(\%)$ & $\mathrm{C}(\%)$ & $\mathrm{D}(\%)$ \\
\hline 1 & 10 & 1 & 45 & 0.1 \\
\hline 2 & 13 & 3 & 50 & 0.3 \\
\hline 3 & 15 & 5 & 55 & 0.5 \\
\hline
\end{tabular}

Table 3 Result of orthogonal experiment of composition optimization

\begin{tabular}{|c|c|c|c|c|c|c|c|}
\hline & \multicolumn{4}{|c|}{ Factors } & \multicolumn{2}{|c|}{ Results } \\
\hline & & $\mathrm{A}$ & B & $\mathrm{C}$ & $\mathrm{D}$ & $\begin{array}{l}180^{\circ} \text { Peel Strength } \\
(\mathrm{kN} / \mathrm{m})\end{array}$ & $\begin{array}{l}\text { Softening Point } \\
\left({ }^{\circ} \mathrm{C}\right)\end{array}$ \\
\hline \multicolumn{2}{|l|}{1} & 10 & 1 & 45 & 0.1 & 0.63 & 72 \\
\hline \multicolumn{2}{|l|}{2} & 10 & 3 & 50 & 0.3 & 0.67 & 67 \\
\hline \multicolumn{2}{|l|}{3} & 10 & 5 & 55 & 0.5 & 1.33 & 73 \\
\hline \multicolumn{2}{|l|}{4} & 13 & 1 & 50 & 0.5 & 0.79 & 75 \\
\hline \multicolumn{2}{|l|}{5} & 13 & 3 & 55 & 0.1 & 1.10 & 72 \\
\hline \multicolumn{2}{|l|}{6} & 13 & 5 & 45 & 0.3 & 1.35 & 78 \\
\hline \multicolumn{2}{|l|}{7} & 15 & 1 & 55 & 0.3 & 1.07 & 73 \\
\hline \multicolumn{2}{|l|}{8} & 15 & 3 & 45 & 0.5 & 1.33 & 79 \\
\hline \multicolumn{2}{|l|}{9} & 15 & 5 & 50 & 0.1 & 1.42 & 89 \\
\hline \multirow{4}{*}{$\begin{array}{c}180^{\circ} \text { Peel } \\
\text { Strength } \\
(\mathrm{kN} / \mathrm{m})\end{array}$} & M1 & 0.88 & 0.83 & 0.91 & 1.05 & & \\
\hline & M2 & 1.00 & 1.03 & 0.96 & 1.03 & & \\
\hline & M3 & 1.27 & 1.37 & 1.17 & 1.15 & & \\
\hline & $\mathrm{R}$ & 0.39 & 0.54 & 0.26 & 0.12 & & \\
\hline \multicolumn{2}{|l|}{ Priority } & \multicolumn{4}{|c|}{$\mathrm{B}>\mathrm{A}>\mathrm{C}>\mathrm{D}$} & & \\
\hline
\end{tabular}


By testing the 180 degree peel strength and softening point of hot-melt pressure sensitive adhesive, the optimum scheme is selected. From the hot-melt adhesive prescription optimization experiment can be seen: Impact of TPU on anti-aging performance of hot-melt adhesive is the biggest, the content of SEBS and tackifying resin impacts peel strength. When SEBS Elastomer content from $10 \%$ up to $15 \%$, the peel strength increased significantly, however, when both rose to a higher proportion, it inevitably reduces naphthenic oil plasticizer agent content, thereby the wettability of hot-melt adhesive will reduce, and the peel strength also will decrease. SEBS content increasing, the hot-melt adhesive softening point was significantly increased. If the softening point is too low, hot-melt adhesive easy to creep. Conversely, it used to increase energy consumption. It is generally controlled within the range of $70-73^{\circ} \mathrm{C}$. Comprehensive analysis, A2B2C2D1 is a better prescription.

Long Term Aging Test. Preparing the product according to the prescriptions, aging experiments were performed under constant temperature and humidity, $180^{\circ}$ peel strength is tested as an indicator.

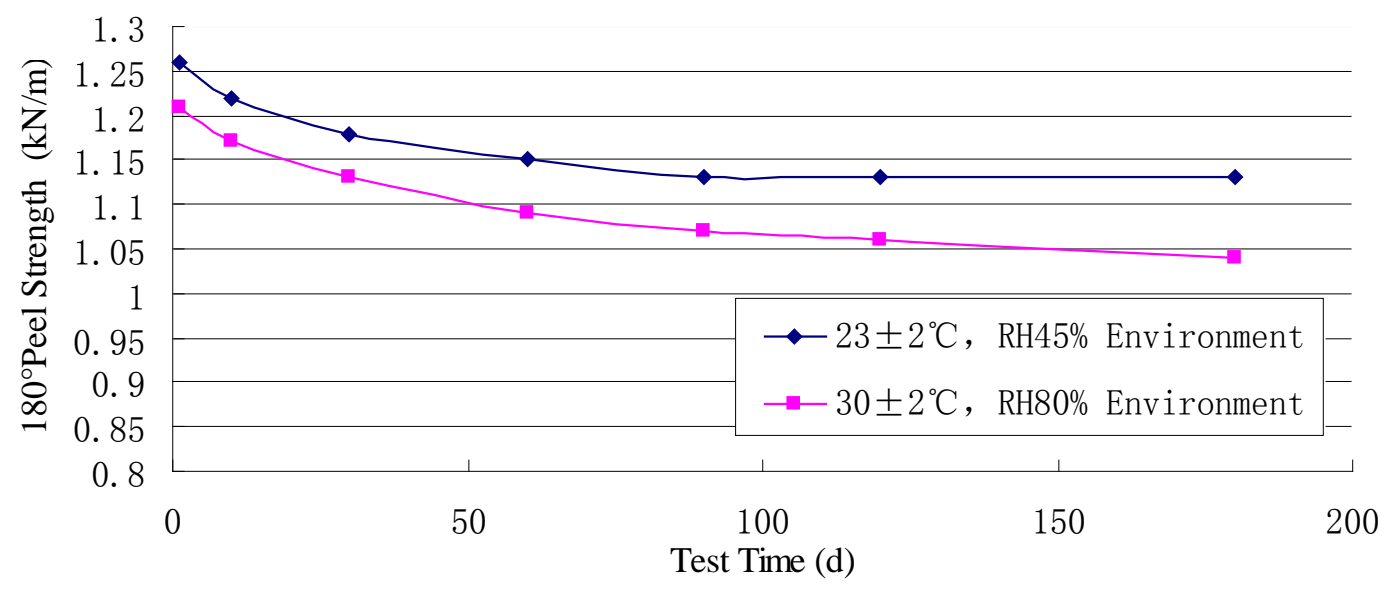

Fig. 4 The long-term peeling strength experimental after optimization of prescription

By test result shows, compared to before the optimization of component, optimization prescription showed better aging resistance In terms of peel strength; at higher temperature and humidity, hot-melt adhesive aging resistant performance slightly worse. In laboratory conditions or simulated summer conditions, 30 days peel strength were reduced with a decrease of amplitude in $3.2 \%-4.1 \%$. Six months peel strength decline amplitude is in 7.1\%-8.3\%.

\section{Conclusion}

The influence of temperature and humidity on the anti-aging performance of hot-melt adhesive is most obvious. The melt viscosity increases with elastomer content increasing. TPU has the largest effect of the anti-aging properties to hot-melt adhesive. Content of SEBS and tackifying resin has the combined effect to the peel strength of hot-melt adhesive. With TPU content of 3\%, SEBS content of $13 \%$ tackifying resin content of $50 \%$, the antioxidant content of $0.1 \%$, the comprehensive anti-aging ability of hot-melt adhesive is strong. Although the bond strength in hot and humid environment is still slightly lower than that in the lab environment, comparing to the previous prescriptions, the bonding properties of improved prescriptions dramatically increased. 


\section{References}

[1] R.P. Singh, A. Vishwa Prasad, S.S. Solanky, The oxidative degradation of styrenic copolymers: A comparison of photoproducts formation under natural and accelerated conditions, J. Journal of Applied Polymer Science, 85(2002)1676-1682.

[2] Emerson Lourenco, Maria Isable Felisbert, i-Photochemical aging of insitu-polymerized blends of polystyrene and poly [acrylonitrile-g-(ethylene-co-propylene-co-diene)-g-styrene](AES), J. Polymer Degradation and Stability, 91(2006)2968-2978.

[3] Brown. K, Hooker. J.C, Creton. C, Fabrication of poly(methyl methacrylate) microsphere added pressure-sensitive adhesives and their physical characteristics, J. Macromol Mater Eng, 287(2002)163-179.

[4] W.J. GUO, H.Q. FU, Y.F. LI, Study on the Mechanical and Adhesive Properties of Waterborne Polyurethane with Multiple Modifications, J. Journal of Chemical Engineering of Chinese Universities, 2(2009)246-251. 